\title{
ELECTROCARDIOGRAPHIC PATTERNS OF COMBINED VENTRICULAR STRAIN
}

\author{
BY \\ R. LANGENDORF, M. HURWITZ, AND L. N. KATZ * \\ From the Cardiovascular Department, Michael Reese Hospital, Chicago, Il., U.S.A. \\ Received August 6, 1942
}

The characteristic electrocardiographic patterns of right and left ventricular strain have been recognized for some time. While originally deviation of the electrical axis, reflected in the direction of QRS in the limb leads, was taken to indicate ventricular hypertrophy $(4,5,7,9-12,16,23-35,28$, $29,37, \& 38)$, later studies showed that the S-T-T pattern $(1,8,22,26,27,30,31,33, \& 41)$ presented the more reliable evidence of chronic ventricular strain and was indicative of ventricular hypertrophy even in the absence of deviation of the electrical axis $(2,19)$. Experience in recent years has shown that the use of multiple chest leads is imperative in distinguishing between records of left ventricular strain and those of myocardial infarction involving the anterior wall $(3,13,14,15,17,20,32, \& 40)$. It has been shown $(6,16,21, \& 24)$ that the patterns of chronic ventricular strain do not necessarily indicate unilateral ventricular hypertrophy, but more often indicate the site of preponderant hypertrophy, or what is equivalent, the site of greater ventricular strain. The occurrence of cardiograms presenting a combination of features characteristic of both right and left ventricular strain suggested to us that bilateral ventricular strain might be reflected on occasion in the cardiogram. We therefore undertook to analyse the various possible patterns suggestive of combined strain and to correlate them with the clinical and autopsy data.

The cases for this study were selected at random from the files of the Heart Station of the past few years. Records showing evidence of myocardial infarction, acute cor pulmonale, or digitalis effect were discarded, because these conditions are known to imitate right and left ventricular preponderance in the absence of demonstrable ventricular hypertrophy or to mask the true pattern when hypertrophy is present $(18,21)$. It has also been shown (18) that these conditions may imitate the changes indicative of combined ventricular strain. A total of 47 records (some previously reported) were found and form the basis of this study. They were readily subdivided into 6 patterns (see Table I and Figs. 1 to 4) as follows :

TABLE I

Description and Frequency of the Various Patterns of Combined Ventricular Strain in 47 Cases

\begin{tabular}{|c|c|c|c|c|}
\hline Type & Electrocardiographic Pattern & $\begin{array}{l}\text { Number } \\
\text { of Cases }\end{array}$ & \begin{tabular}{|c|} 
Clinical or Autopsy \\
Evidence of Combined \\
Ventricular Strain
\end{tabular} & Figure \\
\hline I. & $\begin{array}{l}\text { QRS contour of right ventricular prepon- } \\
\text { derance combined with the } S-T-T \text { con- } \\
\text { tour of left ventricular preponderance. }\end{array}$ & 6 & $\begin{array}{c}6 \\
\end{array}$ & Fig. I, B and C \\
\hline II. & $\begin{array}{l}\text { QRS contour of left ventricular preponder- } \\
\text { ance combined with the } S-T-T \text { contour } \\
\text { of right ventricular preponderance }\end{array}$ & 1 & 1 & Fig. $2 \mathrm{C}$ \\
\hline III. & $\begin{array}{l}\text { Concordant pattern of left ventricular } \\
\text { preponderance (QRS upright in the limb } \\
\text { leads with S-T-T abnormalities) }\end{array}$ & 11 & 8 & Fig. $3 \mathrm{~A}$ \\
\hline IV. & $\begin{array}{l}\text { Concordant inverted pattern of heart } \\
\text { strain (QRS inversion in all three limb } \\
\text { leads without any } Q \text { waves present) }\end{array}$ & 7 & 7 & Fig. 3 B \\
\hline V. & $\begin{array}{l}\text { Prominent } S \text { waves in all the limb leads } \\
\text { with the major } Q R S \text { deflection upward } \\
\text { in at least two leads ( } S-T-T \text { abnormal) }\end{array}$ & 3 & 3 & Fig. $3 \mathrm{C}$ \\
\hline \multirow[t]{3}{*}{ VI. } & $\begin{array}{l}\text { Small upright } Q R S_{1} \text { or equiphasic } Q R S_{1} \\
\text { with an } S_{1} \text {, with deep } S \text { waves in leads } \\
\text { II and III greater in size than the up- } \\
\text { ward deflection of } Q R S_{1} \text { in lead I. }\end{array}$ & 18 & 12 & Fig. $4 \mathrm{~A}$ \\
\hline & $\begin{array}{l}\text { One record not fitting into any of the } \\
\text { above described patterns }\end{array}$ & 1 & 1 & Fig. $4 \mathrm{~B}$ \\
\hline & Total number & 47 & 38 & \\
\hline
\end{tabular}

* Aided by the A. D. Nast Fund for Cardiovascular Research and the Nelson Morris Fund. 
Type I. The combination of a $\mathrm{QRS}$ contour of right ventricular preponderance $\left(\mathrm{QRS}_{1}\right.$ mainly inverted, with an $\mathrm{S}$ wave, and $\mathrm{QRS}_{3}$ upright) and an S-T-T contour of left ventricular preponderance $\left(S-T_{1}\right.$ depressed and bowed upward, with $T_{1}$ inverted or diphasic). (Fig. 1, B and C)

Type II. The combination of a QRS contour of left ventricular preponderance $\left(\mathrm{QRS}_{2}\right.$ and $\mathrm{QRS}_{3}$ inverted, with $\mathrm{S}$ waves) and an $\mathrm{S}-\mathrm{T}-\mathrm{T}$ contour of right ventricular preponderance (S-T $\mathrm{T}_{2}$ and $\mathrm{S}-\mathrm{T}_{3}$ depressed, with $\mathrm{T}_{2}$ and $\mathrm{T}_{3}$ inverted). (Fig. $2 \mathrm{C}$ )

Type III. Concordant type of left heart strain (30) (QRS mainly upright in all limb leads, with S- $T_{1}$ and $S-T_{2}$ depressed, and with $T_{1}$ inverted or diphasic). (Fig. $3 \mathrm{~A}$ )

Type IV. Concordant inverted type of heart strain (20) (QRS mainly inverted in all limb leads, but without $Q$ waves). (Fig. 2 B)

Type V. Prominent $\mathbf{S}$ waves in all the limb leads, with either $\mathrm{QRS}_{1}$ or $\mathrm{QRS}_{3}$ mainly upright, associated with an abnormal S-T-T contour. (Fig. $3 \mathrm{C}$ )

Type VI. Small upright or equiphasic $\mathrm{QRS}_{1}$ (the latter with an $\mathrm{S}$ wave), with $\mathrm{QRS}_{2}$ and $\mathrm{QRS}_{3}$ mainly inverted, and with deep $S$ waves larger than QRS $_{1}$. (Fig. 4 A) 4 B)

One interesting case not fitting into any of the above categories will be described below. (Fig.

In 81 per cent of the 47 cases selected, the cardiographic diagnosis of combined strain was substantiated by the clinical, radiological, and, when available, by the autopsy findings.

In most of the cases of the Type I pattern, serial records taken over a period of years were available, and the gradual evolution of this pattern could be followed (Fig. 1). All 6 were instances of old rheumatic mitral valvulitis; one showed in addition aortic valvular involvement, another showed

A

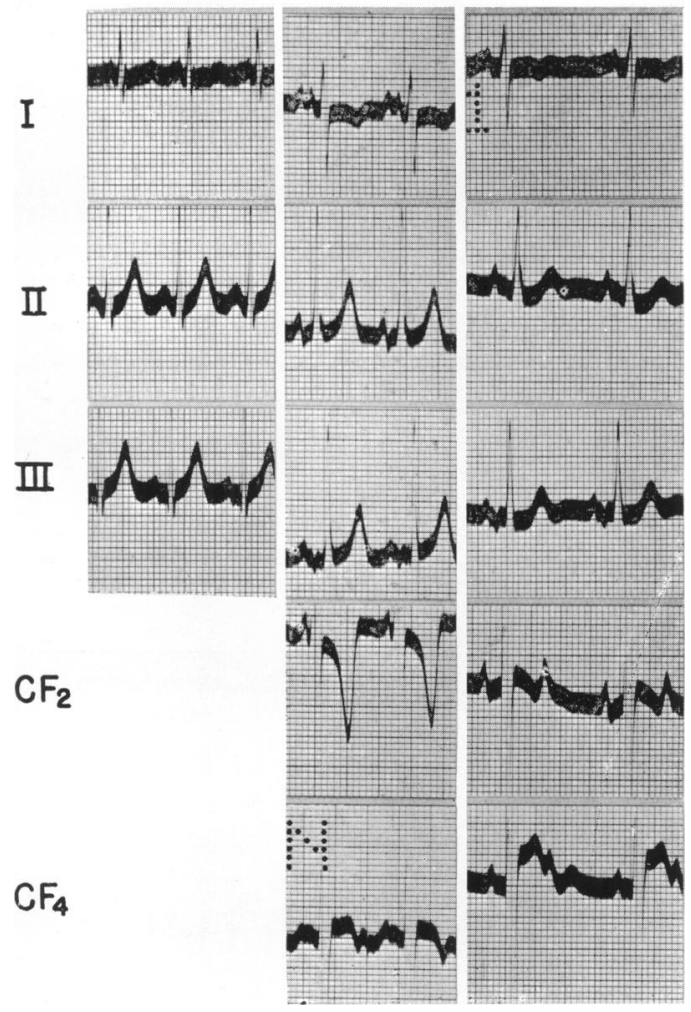

Fig. 1.
A

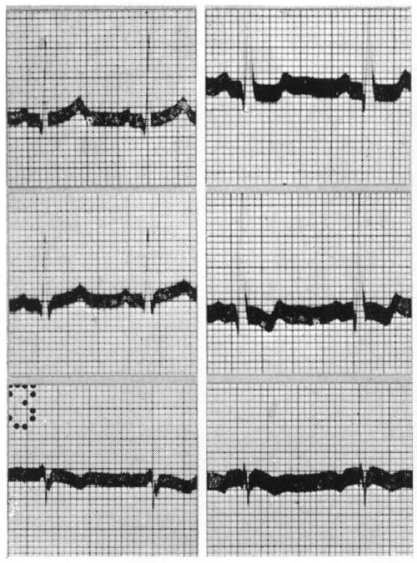

FIG. 2.
C

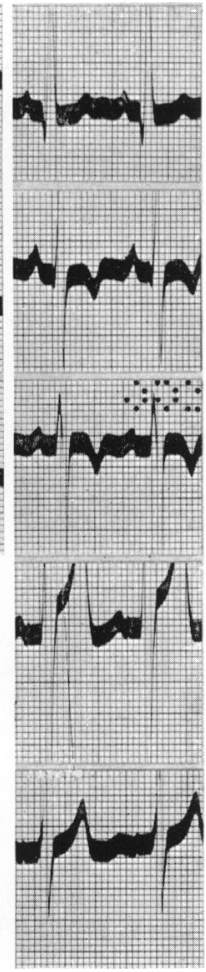

Fig. 1.-The development of the Type I pattern of combined ventricular strain in a patient with rheumatic mitral stenosis and insufficiency and aortic insufficiency. (A), taken at the age of 3 , shows no axis deviation; (B) and (C), taken 3 and 4 years later, show a QRS pattern of right ventricular strain with an S-T-T pattern of left ventricular strain. Note the broad and notched " mitral " $P$ waves.

FIG. 2.-The development of the Type II pattern of combined ventricular strain in a patient with rheumatic heart disease with mitral and aortic stenosis and insufficiency and a tricuspid lesion. (A), taken at the age of 14, shows a normal left axis shift. (B), taken 1 year later, shows an S-T-T contour in leads II and III which does not fit the contour of left ventricular preponderance of lead 1. (C), taken 7 years later, shows a QRS contour of left ventricular preponderance with $T$ inversion in leads II and III, characteristic of right ventricular preponderance. Note the progressive widening of QRS between (A), (B), and (C). 
deformity of the other three valves, and a third showed marked pulmonary emphysema. In two of the six cases autopsy findings corroborated the clinical diagnoses and the bilateral ventricular enlargement.

Only one example of the Type II pattern was encountered. This boy, aged 21, had clinical evidence of severe rheumatic carditis with mitral and aortic stenosis and insufficiency and a probable tricuspid lesion. Numerous records taken over thirteen years showed progressive inversion of QRS in leads II and III with inversion of $\mathrm{T}$ in those leads (Fig. 2). Digitalis was never given to this patient.

Kaplan and Katz (1941) in their description of the so-called concordant pattern of left heart strain suggested that the absence of axis deviation might be due to concomitant right ventricular strain, either on the basis of episodes of left ventricular failure (36) or an associated lesion putting a strain primarily on the right ventricle. They collected 17 cases and showed that 4 were attributable to combined mitral and aortic lesions, 9 to hypertensive heart disease with previous episodes of left ventricular failure, 2 to syphilitic aortic insufficiency with failure, and in the remaining 2 only hypertension was evident with no previous congestive heart failure. In one of the latter, the absence of axis shift was attributed to a displacement of the heart and mediastinum to the right by a massive pleural effusion.

A

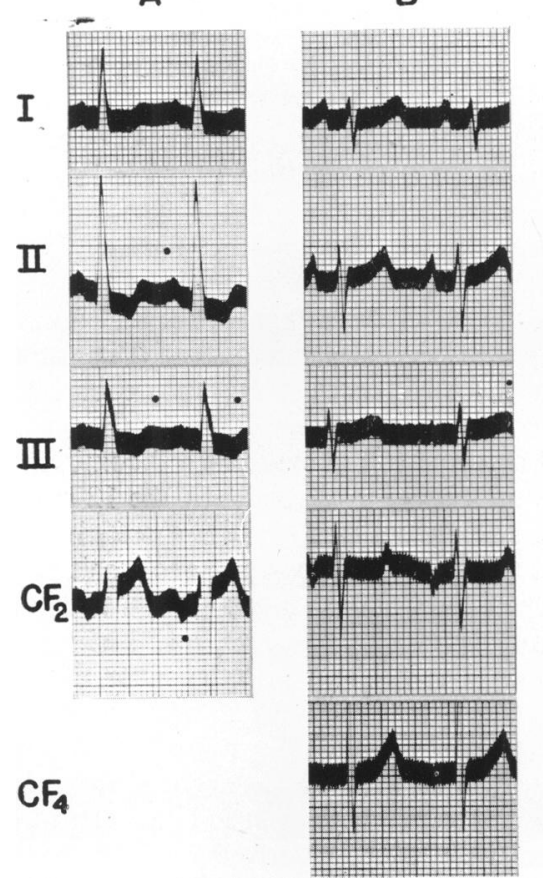

C

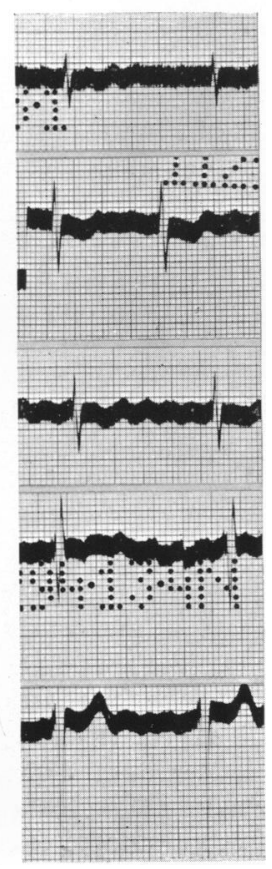

Fig. 3.

A

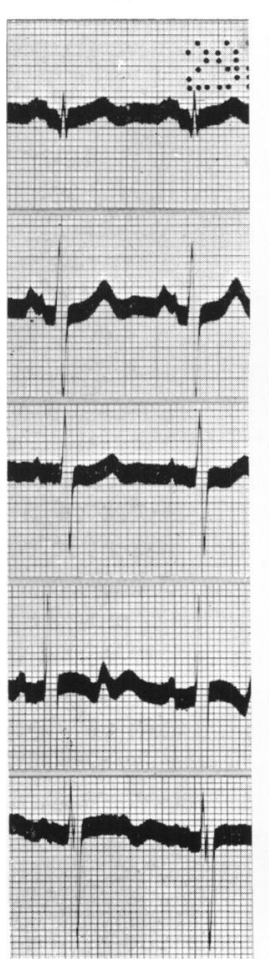

B

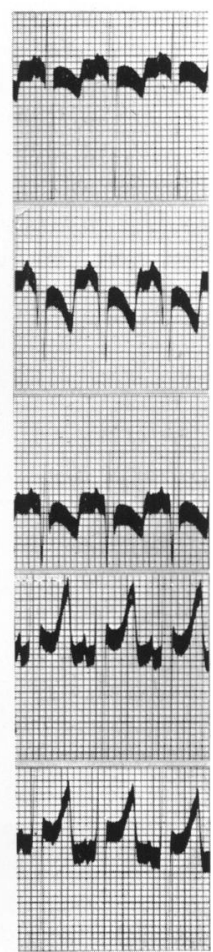

FIG. 4.

Fig. 3.-Three different patterns of combined ventricular strain. (A) shows the "concordant type of left ventricular preponderance" (Type III pattern of combined ventricular strain) in a 35 year old patient with hypertension and chronic emphysema. Heart weight at autopsy was $830 \mathrm{~g}$., all chambers being dilated and hypertrophied. Note S-T depression and T inversion in all the limb leads as well as absence of axis deviation. (B) shows the " concordant inverted type of heart strain" (Type IV pattern of combined ventricular strain) in a 1 year old patient with mitral stenosis and insufficiency. QRS is of the $\mathbf{S}$ type in

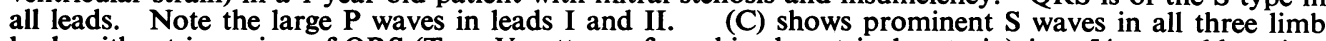
leads without inversion of QRS (Type V pattern of combined ventricular strain) in a 54 year old patient with stenosis and insufficiency of the mitral and aortic valves, hypertension, and emphysema and auricular fibrillation.

FIG, 4.- (A) shows the Type VI pattern of combined ventricular strain diagnosed on the basis of a small upright QRS in lead I and diphasic QRS complexes in leads II and III with deep S waves. The record was taken on a patient of 25 with mitral and aortic stenosis and insufficiency. Note the normal QRS contour in the chest leads and the typical " mitral" $P$ wave pattern in limb and chest leads. (B) was taken on a three month old infant with Von Gierke's disease and marked cardiac enlargement, proven at autopsy. Combined ventricular strain was diagnosed because of the S-T depressions and T inversions in all limb leads. Note the large diphasic QRS complex in lead I. 
In our 11 cases of this Type III pattern (Fig. $3 \mathrm{~A}$ ), 8 were accounted for on the basis of combined heart strain; 3 of these were in cases of hypertension and chronic cor pulmonale due to asthma, bronchiectasis, and emphysema; 3 were due to combined mitral and aortic valvular lesions; 1 was due to hypertension combined with mitral stenosis; and the last was a case of severe hypertension with pulmonic valvular incompetence, either organic or functional. Of the 3 remaining cases, one had only hypertension, although X-ray showed enlargement both to the right and left, another had hypertension with only left-sided enlargement, and the third had only left ventricular hypertrophy with displacement of the heart and mediastinum to the right by massive pleural effusion from a pleural fibrosarcoma (reported with autopsy by Kaplan and Katz, 1941). Two of the cases, one with hypertension and emphysema and one with combined valvular disease, also came to autopsy, the hearts weighing 675,725 , and $830 \mathrm{~g}$. respectively and showing bilateral ventricular hypertrophy.

None of the 7 cases with concordant inversion of the QRS in the limb leads showed true Q waves (Type IV). In the only case coming to autopsy, bilateral ventricular enlargement was present in association with an inter-atrial septal defect, the ætiology of the left ventricular enlargement not being evident. In all of the remaining 6 there was clinical evidence of bilateral strain. One of these appeared to be due to a combination of severe hypertension and chronic emphysema on a 1 asthmatic basis, while a second (Fig. 3 B) had rheumatic mitral stenosis and insufficiency to account for the combined strain, although X-ray showed only slight cardiac enlargement. In the remaining 4 cases, congenital heart disease was present, 2 of these having an associated rheumatic mitral stenosis and regurgitation. The relative frequency of congenital heart disease in this type is striking, and one must consider the possibility that the abnormally directed QRS complexes may represent a congenitally abnormal pathway for the spread of the impulse rather than evidence of bilateral ventricular strain, although the latter is often present in congenital heart disease. This Type IV pattern is present in many of Schnitker's (1940) autopsy series of 106 cases of congenital cardiac disease.

There were 3 cases of the Type $V$ pattern. These are similar to the preceding patterns in that $\mathbf{S}$ waves are present in all the limb leads, but differ in that the major deflection is not directed downward in all the limb leads. One of these came to autopsy and showed bilateral ventricular hypertrophy due to mitral and aortic lesions and in addition a patent foramen ovale. In the other two, $\mathrm{X}$-ray showed cardiac enlargement both to the right and left. Both of these had mitral and aortic lesions with stenosis and regurgitation; one of them also had hypertension and emphysema (Fig. $3 \mathrm{C}$ ). The criteria for the differentiation of records such as these from those instances of normally occurring $\mathrm{S}$ waves in all the limb leads have already been discussed (39).

There were 18 instances of the Type VI pattern. Clinical or autopsy evidence of combined ventricular strain was present in two-thirds of these, autopsies of 7 being available. Of the 12 cases with combined strain, 3 had emphysema and hypertension, 3 had mitral stenosis and insufficiency, 2 had deformities of both mitral and aortic valves (Fig. 4 A), 1 showed severe coronary sclerosis and myocardial fibrosis with bilateral ventricular hypertrophy (heart weight $500 \mathrm{~g}$. at autopsy), 1 showed bilateral hypertrophy (heart weight $475 \mathrm{~g}$. at autopsy) with no demonstrable cause, and 2 showed bilateral hypertrophy with emphysema to explain that of the right ventricle, while the cause of the left ventricular hypertrophy was not disclosed. In the remaining 6 of this type none showed evidence, either clinically or anatomically, of combined ventricular hypertrophy, and only one showed any cardiac enlargement at all, this being in an autopsied case of emphysema with marked right ventricular enlargement. In two other cases, pulmonary emphysema was present with a resultant vertically placed heart which was not enlarged; another autopsied case showed brown atrophy of the myocardium with no other abnormalities; and in the last two cases of this group, one of which came to autopsy, there were no abnormal cardiac findings although the position of the heart was not recorded.

The frequency of pulmonary emphysema in cases showing this cardiographic pattern was striking, being present in 8 of the 18 cases ( 45 per cent). In these cases there was a vertically placed heart and a rotation of the heart on its longitudinal axis from right to left due to the low position of the diaphragm. It has been shown $(18,35)$ that this position change may be the sole abnormality in cases having this cardiographic contour, and this may be the mechanism in 3 of our cases with normalsized hearts. Since emphysema also was present in 5 of the cases that had bilateral ventricular strain, it is possible that cardiac displacement played the major role in determining the abnormal QRS contours. However, the fact that this pattern occurred in 7 cases of bilateral enlargement without emphysema indicates that combined strain does give rise to this pattern per se.

The last record (Fig. 4 B) which did not fit any of the above patterns was taken from a three month old infant with Von Gierke's disease (confirmed by autopsy) in whom the heart was massively enlarged. The diagnosis of combined strain was based primarily on the depression of the S-T segments and deep inversion of the $T$ waves in all the limb leads associated with a large equiphasic $Q_{R} S_{1}$ with deep $\mathbf{S}_{1}$.

In order to estimate the frequency of the cardiographic patterns suggestive of combined ventricular 
strain which occur in combined ventricular hypertrophy, a series of 149 consecutive autopsies in which cardiograms were available (Katz et al, 21) were reviewed. After eliminating cases with myocardial infarction, acute cor pulmonale on the basis of massive pulmonary embolism, and intraventricular block (QRS duration of $0.12 \mathrm{sec}$. or more) in the cardiogram, 29 cases remained in which the hearts were enlarged and both ventricles hypertrophied. The distribution of the patterns is shown in Table II. In over 25 per cent. of the cases with bilateral ventricular hypertrophy evidence

TABLE II

Cardiographic Contours in 29 autopsied Cases of Bilateral Ventricular Hypertrophy

\begin{tabular}{|c|c|c|c|c|}
\hline Cardiographic Pattern & & & No. of Cases & Percentage of Series \\
\hline $\begin{array}{l}\text { No axis shift or normal right or left axis shift } \\
\text { Left ventricular preponderance } \\
\text { Right ventricular preponderance } \\
\text { Combined ventricular strain }\end{array}$ & $\begin{array}{ll}t & . . \\
. . & . \\
. . & \cdots \\
. . & \end{array}$ & $\begin{array}{l}\cdots \\
\because \\
\cdots\end{array}$ & $\begin{array}{c}10 \\
8 \\
3 \\
8^{*}\end{array}$ & $\begin{array}{l}35 \\
27 \cdot 5 \\
10 \\
27 \cdot 5\end{array}$ \\
\hline
\end{tabular}

* The eight records showing evidence of combined ventricular strain fell into the following types (see Table I): 2 into Type I, 2 into Type III, 1 into Type IV, 1 into Type V, and 2 into Type VI.

of this is visible in the cardiogram. It is thus apparent that the occurrence of these particular patterns should suggest the possibility of combined ventricular strain, when myocardial infarction, acute cor pulmonale, and digitalis effect have been ruled out, provided, of course, that the QRS duration is normal. Obviously, when there is clinical and radiological evidence of cardiac enlargement and the cardiogram shows no evidence of preponderance or only a normal right or left axis shift (as in 35 per cent of our autopsied series (Table II)), bilateral ventricular strain may still be present, the assumption being that the pattern of strain on one ventricle neutralizes that of the other almost completely. Furthermore, while these patterns are suggestive of combined ventricular strain, and in the cardiographic series analysed were substantiated clinically and by autopsy in 81 per cent of the cases, it does not follow that the pattern is directly due to the hypertrophy of both ventricles. In some instances the displacement of the heart and its rotation on its various axes may contribute to these so-called combined strain patterns. Furthermore, in some instances, it is not at all impossible that disseminated focal lesions may sufficiently alter the spread of the impulse to give rise to these patterns without accompanying prolongation of the total invasion time. This may also be brought about in congenital heart disease, by a congenitally abnormal placement of the conduction system. Until such a time as more definite evidence is available, the exact mechanism leading to these patterns must be considered sub judice. This, however, does not nullify the diagnostic significance of such records.

\section{SuMmaRY AND CONCLUSIONS}

An analysis of 47 cases showing a combination of features of right and left ventricular strain in the cardiogram is presented. These were then correlated with clinical data and, in 19 instances, with the available autopsy findings.

Six electrocardiographic patterns of combined ventricular strain are described.

The cardiographic diagnosis of combined ventricular strain was substantiated by clinical, radiological, or post-mortem evidence in 81 per cent of the cases.

In a control group of 29 autopsied cases of bilateral ventricular hypertrophy in the absence of myocardial infarction, acute cor pulmonale, intra-ventricular block, or digitalis effect in the cardiogram, cardiographic evidence of combined strain was present in 27.5 per cent. In 35 per cent of the same series no ventricular preponderance and no axis deviation or only normal right or left axis shift were present; this substantiates the statement that absence of ventricular preponderance in the cardiogram in the presence of clinical or radiological evidence of cardiac enlargement is presumptive evidence of combined ventricular strain.

Other factors like displacement of the heart, congenital anomaly of the conduction system, or focal intraventricular block may be responsible for a pattern suggestive of combined ventricular strain.

Further anatomical correlation studies are necessary to establish the diagnostic accuracy of the cardiographic patterns of combined ventricular strain. 


\section{REFERENCES}

1. Barnes, A. R., and Whitten, M. B. (1929). Amer. Heart J., 5, 14.

2. Barnes, A. R. (1940). Electrocardiographic Patterns, Their Diagnotic and Clinical Significance. Baltimore.

3. Bohning, A., Katz, L. N., Robinow, M., and Gertz, G. (1939). Amer. Heart J., 18, 25.

4. Burger, R. (1926). Z. klin. Med., 102, 603.

5. Carter, F. P. and Greene, C. H. (1919). Arch. intern. Med., 24, 638.

6. Cotton, T. F. (1917). Heart, 6, 217.

7. Dieuaide, F. R. (1921). Arch. intern. Med., 27, 558.

8. Dunis, E., Hecht, H., and Korth, C. (1938). Dtsch. Arch. klin. Med., 181, 539.

9. Einthoven, W. (1906). Arch. internat. Physiol., 4, 132.

10. Einthoven, W., Fahr, G., and de Waart (1908). Arch. ges. Physiol., 122, 517.

11. Einthoven, W., Fahr, G., and de Waart (1913). Arch. ges. Physiol., 150, 275.

12. Fahr, G. (1921). Arch. intern. Med., 27, 126.

13. Freundlich, J. and Lepeschkin, E. (1939). Cardiologia, 3, 331.

14. Groedel, P. M. (1934). Das Extremitaten-, Thorax- und Partial-Elektrokardiogramm des Menschen, Dresden und Leipzig.

15. Hecht, H. (1936). Arch. klin. Med., 179, 1.

16. Herrmann, G. R. and Wilson, F. N. (1922). Heart, 9, 91.

17. Holzmann, M. (1936). Arch. Kreislauff, 1, 2.

18. Hurwitz, M. M., Langendorf, R., and Katz, L. N. (In press). The Diagnostic QRS Patterns in Myocardial Infarction.

19. Kaplan, L. G., and Katz, L. N. (1941). Amer. J. med. Sci., 201, 676.

20. Katz, L. N. (1941). Electrocardiography, Philadelphia.

21. Katz, L. N., Goldman, A. M., Langendorf, R., Kaplan, L. G., and Killian, S. T. (In press). Amer. Heart $J$.

22. Korth, C., and Proger, S. H. (1931). Dtsch. Arch. klin. Med., 170, 516.

23. Krumbhaar, E. B. and Jenks, H. H. (1917). Heart, 6, 189.

24. Lewis, T. (1914). Heart, 5, 367.

25. Lewis, T. (1916). Phil. Trans. Roy. Soc., 207, B, 221.

26. Master, A. M. (1930). Amer. Heart J., 5, 291.

27. Master, A. M. (1933), Amer. J. med. Sci., 186, 715.

28. Pardee, H. E. B. (1920). Arch. intern. Med., 25, 683.

29. Proger, S. H. and Davis, D. (1930). Arch. intern. Med., 45, 974.

30. Proger, S. H. and Korth, C. (1931). Dtsch. Arch. klin. Med., 171, 578.

31. Proger, S. H. and Minnich, W. R. (1935). Amer. J. med. Sci., 189, 674.

32. Roth, I. R. (1937). Amer. Heart J., 14, 155.

33. Rykert, H., and Hepburn, J. (1935). Amer. Heart J., 10, 942.

34. Schnitker, M. A. (1940). Electrocardiogram in Congenital Cardiac Disease. Cambridge, Mass.

35. Sodeman, W. A. and Burch, G. E. (1938). Amer. Heart J., 15, 490.

36. Thompson, W. P., and White, P. D. (1936). Amer. Heart J., 12, 641.

37. White, P. D. and Bock, A. V. (1918). Amer. J. med. Sci., 156, 17.

38. White, P. D., and Burwell, C. S. (1924). Arch. intern. Med., 34, 259.

39. Wilburne, M., and Langendorf, R. (In press). Electrocardiogram with Prominent $S$ Waves.

40. Wilson, F. N., Johnston, F. D. Cotrim, N., and Rosenbaum, F. F. (1941). Trans. Ass. Amer. Physicians, 56, 258.

41. Winternitz, M. (1932). Z. klin. Med., 119, 632. 